\title{
Population monitoring of Epischura baikalensis Sars, 1900 in Maloye More Strait (Lake Baikal)
}

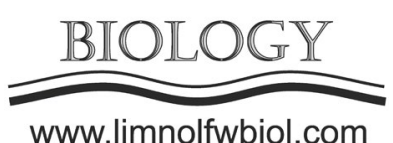

\author{
Sheveleva N.G., ${ }^{1, *}$, Penkova O.G. ${ }^{2}$, Makarkina N.V. ${ }^{2}$ \\ ${ }^{1}$ Limnological Institute, Siberian Branch of the Russian Academy of Sciences, Ulan-Batorskaya Str., 3, Irkutsk, 664033, Russia \\ ${ }^{2}$ Irkutsk State University, Karl Marx Str., 1, Irkutsk, 664003, Russia
}

\begin{abstract}
The article presents the long-term observations data (1997-2017) on the population dynamics of the endemic planktonic copepod Epischura baikalensis in Maloye More Strait (Lake Baikal) under new environmental conditions, such as global climate warming, low water level period and increased anthropogenic load. We give a full description of the morphological features of females and males. We show that, like in the open pelagic zone of the lake, the population of $E$. baikalensis inhabiting Maloye More Strait has two generations in the year cycle. Epishura plays a leading role in the zooplankton quantitative indicators of the strait, which is typical for Lake Baikal in the whole. The values of the abundance and biomass of the epishura population in Maloye More Strait for the period of our observations fit into the amplitude of the long-term oscillations typical of open Baikal.
\end{abstract}

Keywords: morphology, biology, long-term dynamics, Epischura baikalensis, Maloye More Strait (Lake Baikal)

\section{Introduction}

Long-term seasonal spatial dynamics of zooplankton in the open pelagic zone of Lake Baikal is well studied. The bulk of Baikal zooplankton is rotifers and crustaceans. The endemic copepod Epischura baikalensis Sars is the most important representative of crustaceans, which comprises up to $80-90 \%$ of the number and biomass of zooplankton. An analysis of the population dynamics of epishura is necessary for the sustainability of the ecological system in the lake (Kozhova, 1971; 1991; Kozhova and Pavlov, 1985). According to Kozhova (1991), zooplankton monitoring should be based on the investigations of the spatial and temporal variability of the structure populations of dominant species. Obviously, the contribution of some groups and species to the total number and their different dependence on water temperature determine the long-term dynamics of zooplankton. Endemic epishura prefers the cold waters of open Baikal, where it dominates throughout the year, and it appears in bays and sors of the lake only in the ice and spring periods. However, now, in addition to the natural environmental factors that determine the functioning of the planktonic community, there are new ones with the unknown consequences. They are global warming and low water level period (Kuimova et al., 2015). Since 2011, there has been an increase in water temperature over most of the Baikal water area (Shimaraev et al., 2015). Most current publications show a change in the structure of the Baikal zooplankton in the summer towards an increase in thermophilic species (Hampton et al., 2008; Pislegina and Zilov, 2009; Izmesteva et al., 2016; Bondarenko and Logacheva, 2017).

Since the beginning of the century, the anthropogenic load on the Baikal ecosystem has been significantly increasing, which has primarily affected the shallow zone of the lake. Maloye More Strait now exhibits the enhanced recreational pressure. According to the recent data, the ecological crisis is developing in the vast shallow waters of the strait (Timoshkin et al., 2015). In the past and this century, special studies on the state of the epishura population have been sporadic and not numerous (Afanasyeva, 1973; 1977a; Kozhov and Pomazkova, 1973; Pavlov and Pislegina, 2004; Pislegina et al., 2004; Pislegina, 2010; Sheveleva and Penkova, 2018), and, in particular, such data are not available for Maloye More Strait. In 1997, we have initiated regular studies of zooplankton in the southern part of Maloye More Strait that are still ongoing (Sheveleva and Penkova, 2005; 2018; Sheveleva et al., 2009).

This work is aimed at the analysis of longterm dynamics of quantitative indicators of the $E$. baikalensis population and the characteristics of its life cycle in Maloye More Strait under new environmental conditions.

*Corresponding author.

E-mail address: shevn@lin.irk.ru (N.G. Sheveleva)

(C) Author(s) 2018. This work is distributed under the Creative Commons Attribution 4.0 License. 


\section{Materials and methods}

Studies of long-term dynamics of quantitative indicators of the E. baikalensis population were conducted in the open part of Maloye More Strait (53'05'20,7'N; 106 54'38,7'E) in 1997-2017. Samples were taken from May to October in the daytime, and only in 2002 the sampling was additionally carried out in the ice period (March). Zooplankton was collected by the Juday net (diameter of openings was $37.5 \mathrm{~cm}$ and mesh widths were $100 \mu \mathrm{m}$ ). The upper $25-\mathrm{m}$ layer was caught above a depth of more than $100 \mathrm{~m}$. At the same time, the surface water temperature and transparency were measured. Laboratory investigations were carried out according to the standard method (Kozhova and Melnik, 1978). In the epishura population, all stages of development (orthonauplii, metanauplii, copepodite instars and adults) were calculated. To calculate the zooplankton biomass, individual weights shown for Baikal organisms were used (Kozhova and Melnik, 1978).

The total number and biomass of all zooplankton, as well as the epishura population, were calculated as arithmetic averages over a period of May-October for each year separately.

To study the morphology of crustaceans, a Philips SEM 525M (Philips, Holland) scanning microscope was used. Copepods were photographed on the basis of the Collective Instrumental Center "Ultramicroanalysis" at the Limnological Institute of the Siberian Branch of RAS.

\section{Results and discussion}

There is a species description and images of appearance, details of the structure of the fifth leg in female and male as well as the structure of the oral appendages of epishura (Sars, 1900; Garber, 1941; Afanasyeva, 1977b; 1995). There are detailed schemes of habit view and description of nauplial stages, from stage 1 to stage 6 (Afanasyeva, 1977a; 1995). Later publications discussed particular study issues: the morphology and structure of the mandibles in four epishura species, including Baikal species (Naumova et al., 2015; Zaidykov, 2016). The analysis of mitochondrial genes (COI) resolved the issue of a single population in Lake Baikal (Zaidykov et al., 2015). Our studies using scanning electron microscopy (SEM) have added a description of morphological parts of adult male and female epishura. We have shown the armament of maxillipeds and maxillules (Fig. 1D, 1E). We have also shown the armament of female spines on the exopodite II (Exp II). These spines are covered with small sensory spines located vertically and horizontally (Fig. $1 \mathrm{G}, 1 \mathrm{H}$ ). In male, the surface of the abdomen segments 2 and 3 has a dotted pattern (Fig. 2C), below which, on segment 5 , there is a rounded plate-like protuberance with five peaks (Fig. 2B). The fifth leg of male is asymmetric; the left leg (Fig. 2E 1; 2F) is much larger than the right one (Fig. 2E 2, 2D). Basipodite (Bsp) of the right leg in the distal part is wide with 3-4 small spinelets (Fig. 2D). The distal part of exopodite (Exp) of the right leg is blunt ending with a small spine (Fig. $2 \mathrm{G}, 2 \mathrm{H}, 2 \mathrm{I}$ ) and indented plate.

According to Kozhov (1962) and Afanasyeva (1977b; 1995), during a year epishura produces two generations in the pelagic zone of Lake Baikal. Our data have shown that in Maloye More Strait epishura also has two generations in the year cycle (Fig. 3). In the ice period, nauplii represented up to $100 \%$ of the winter and spring epishura population. However, already in mid-June with a temperature of less than $5^{\circ} \mathrm{C}$ the copepodite instars dominated the population. Moreover, the bulk was copepodites of instars I-II (36\%) and III-IV (14\%). Additionally, there were copepodites of instar V and adults. In July, we observed the second peak of the nauplii number due to the summer generation (Fig. 3). Like in open Baikal, in Maloye More Strait, the summer population develops faster than the winter and spring one. Since mid-August and September, already late copepodites (72-74\%) dominated plankton, and adults appeared. At the end of September and in October, the winter and spring generation began to regress. In Maloye More Strait, as in the open pelagic zone of the lake, epishura of all instars can be found at any time of the year. According to Kozhov (1962) and Afanasyeva (1995), this is due to the fact that during the year the epishura population has two generations, and females lay eggs in portions. In such conditions, copepods of several litters represent each generation. Therefore, we have shown that in Maloye More Strait, like in the open pelagic zone (Afanasyeva, 1977a; 1995), E. baikalensis has two generations during the year.

Based on long-term observations (19972017), we have shown that epishura was the bulk of zooplankton in Maloye More Strait (Fig 4). Previously, Kozhov (1962) and Afanasyeva (1977a) indicated that the optimum water temperature for epishura development is $7^{\circ} \mathrm{C}$; therefore, it is rather natural to expect its maximum abundance during the colder season. Thus, during the ice and early spring periods its share was up to $75-85 \%$ of the total number and up to $90 \%$ of the total mass. During the ice-free period (May-November), the long-term share of epishura in the abundance of zooplankton community was $19-71 \%$. We recorded relatively maximum abundance of epishura (83\%) in 2012 (Fig. 4). In the general series of observations, the exception was the usual temperature regime of 1999 as well as warm 2002 (Pislegina and Zilov, 2009). In these years, rotifers and the Cyclops kolensis population dominated the fauna of plankton. The share of epishura was less than $1-2 \%$ of the total zooplankton number.

The long-term dynamics of quantitative indicators of epishura in Maloye More Strait was oscillatory, which is typical for Baikal in the whole. The 1997 and 2013 observations stand out of the general series, in which the epishura abundance decreased to the minimum values (0.5-1.7 thousand individuals per $\mathrm{m}^{3}$ ). At the same time, we indicated three peaks of the epishura abundance (2001, 2008 and 2012) with a maximum of 23.6 thousand individuals per $\mathrm{m}^{3}$ in 2001 . Based on the data on annual mean value of weighted average water temperature, 2001 was referred to as a cold year (Kiprushina and Izmestieva, 2009), and 2008 


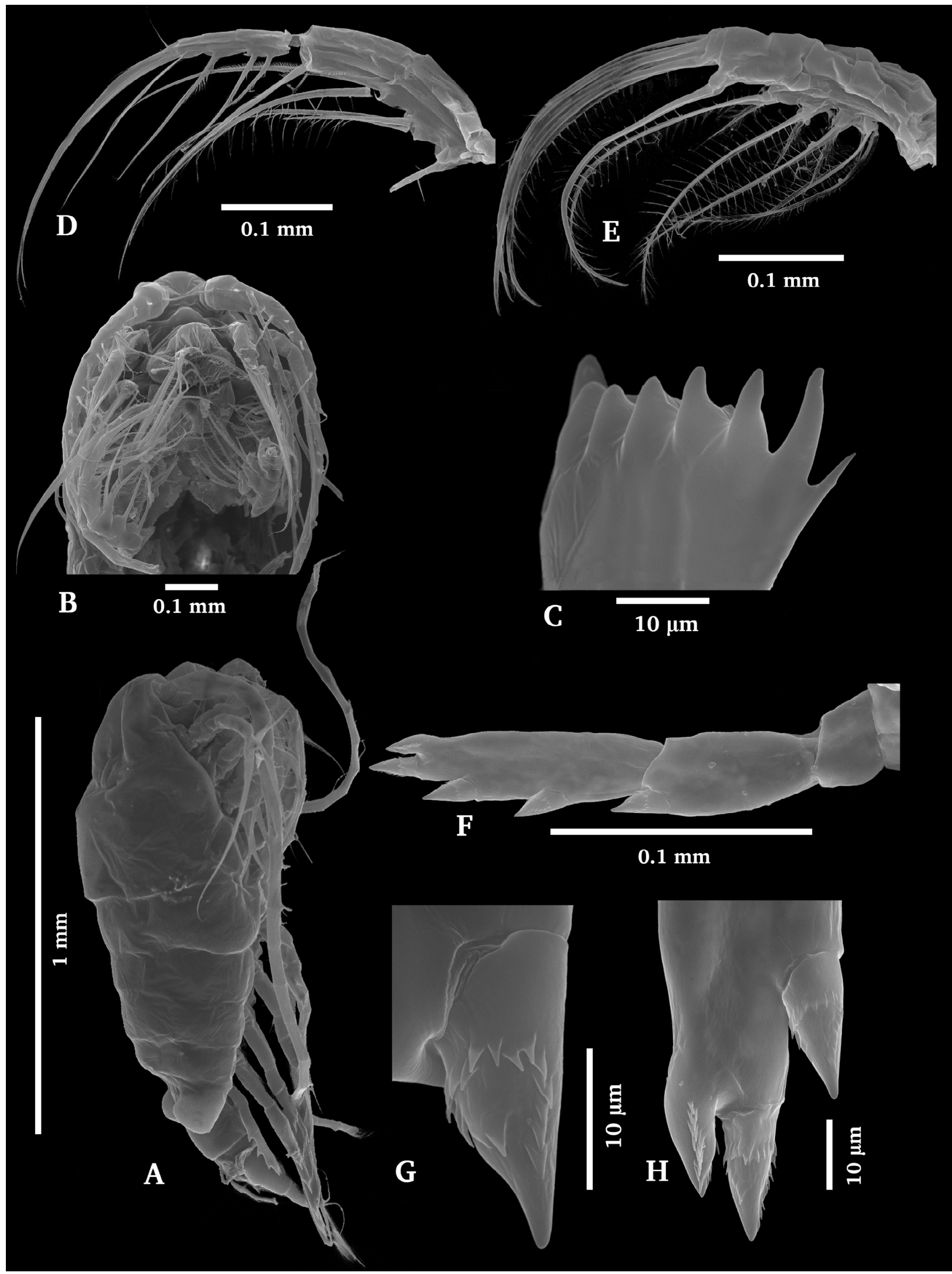

Fig. 1. Epischura baikalensis, female. A - lateral view; B - cephalothorax, ventral view; C - mandible; D - maxilliped; E maxilla; F - P5 leg of female; G - armament of distal spine of Exp II of P5; H - armament of all other spines of Exp II of P5. 


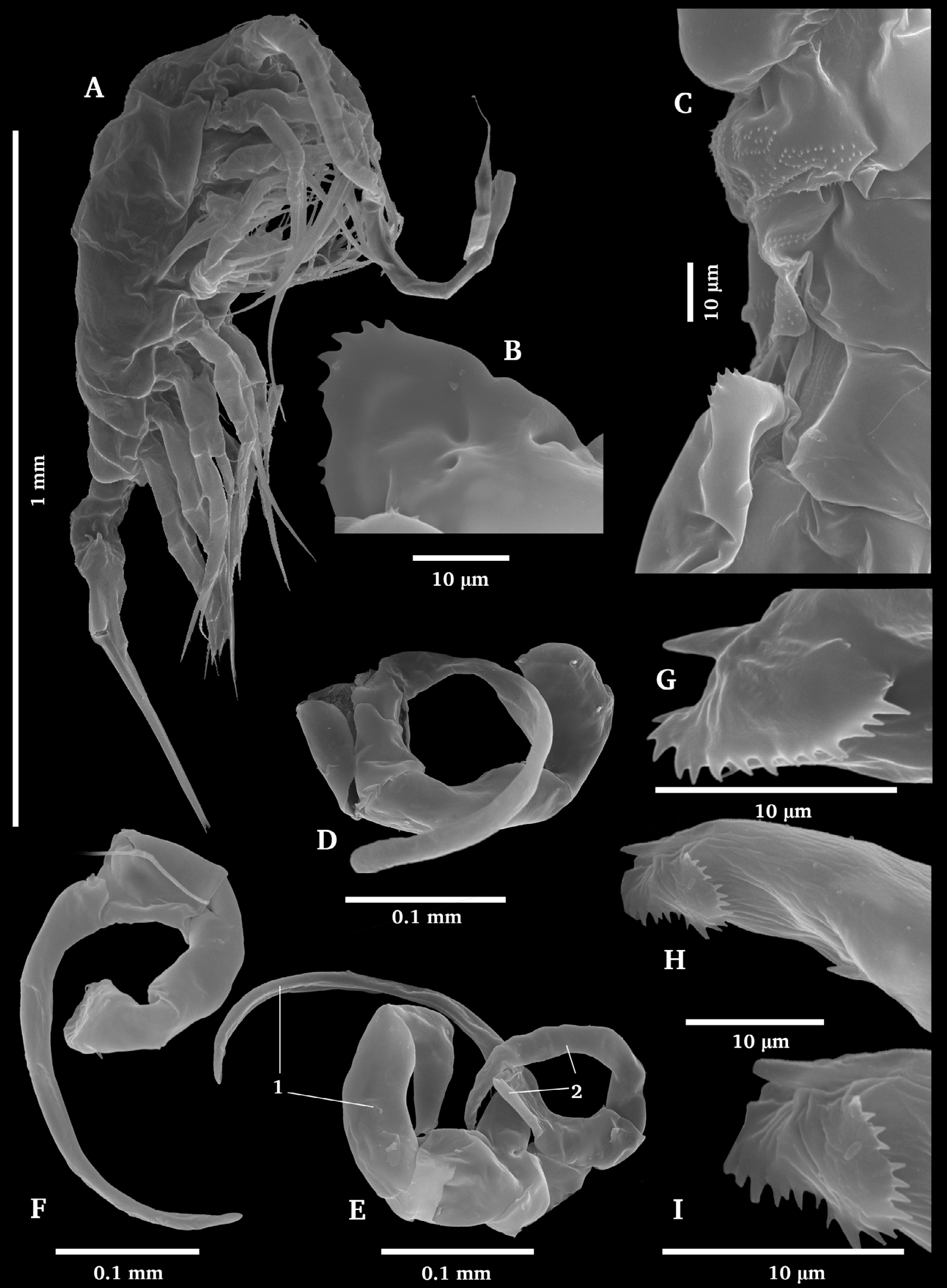

Fig. 2. Epischura baikalensis, male. A - lateral view; B - abdomen projection on segment 5; C - armament of abdomen segments 2 and 3 with a protuberance on abdomen segment 5; D - right P5 leg; E - P5 (1- left leg; 2 - right leg); F - left P5 leg; G, H, I - armament of the apical part of Exp of the right leg. 
and 2012 were warm years (Sheveleva and Penkova, 2018). The previous statistical data proved that epishura abundance poorly depends on water temperature (Sheveleva et al., 2009). In general, the long-term dynamics of the epishura population in Maloye More Strait fully reflects the changes in the abundance of the whole zooplankton in this part of Lake Baikal and demonstrates the emerging trend of a decrease in both, the total number and the epishura population, since 2013.

The confirmation of the above assumptions requires further control of the Baikal endemic epishura.

\section{Conclusions}

The analysis of the long-term dynamics of quantitative data on the E. baikalensis population in Maloye More Strait over a period of our research (1997-2017) fits into the amplitude of the long-term indicators and is comparable with the data for 1951 (Vilisova, 1959) and 1961-1974 (Afanasyeva, 1977a). E. baikalensis plays a leading role in the abundance and biomass of zooplankton, which is typical for Lake Baikal in the whole.

We have shown that, like in the open pelagic zone of the lake, in Maloye More Strait, the E. baikalensis population has two generations in the year cycle.

Long-term studies of quantitative indicators of epishura for the ice-free period have shown three peaks in its development, which were observed in the cold (2001) and warm $(2008,2012)$ years. Over 20 years of observation, maximum density of epishura was indicated in 2001, when it was 23.6 thousand individuals per $\mathrm{m}^{3}$.

\section{Acknowledgements}

The authors are very grateful to E.A. Dolid for the design of figures 1 and 2, and Yu.M. Vitushenko for the translation of the article into English.

The processing of material and preparation of this article was partially supported by the project No. 0345-2016-0010 (AAAA-A16-116122110062-3) "The Influence of Changing Natural and Anthropogenic Factors on Biochemical Processes on the Stony Littoral of Lake Baikal".

\section{References}

Afanasyeva E.L. 1973. The abundance and biomass of zooplankton in Lake Baikal in the 0-50 m layer. In: Smirnov N.N. (Ed.), Long-term indicators of zooplankton development in lakes. Moscow, pp. 176-178. (in Russian)

Afanasyeva E.L. 1977a. Composition, number and production of zooplankton (1961-1974). In: Florence O.N. (Ed.), Biological productivity of the pelagic zone of Lake Baikal and its variability. Novosibirsk, pp. 39-61. (in Russian)

Afanasyeva E.L. 1977b. Biology of Baikal epishura. Novosibirsk: Science. (in Russian)

Afanasyeva E.L. 1995. Copepods of Copepoda subclass, suborder Calanoida. In: Timoshkin O.A. (Ed.), Guide and key to pelagic animals of Baikal. Novosibirsk, pp. 365-405. (in

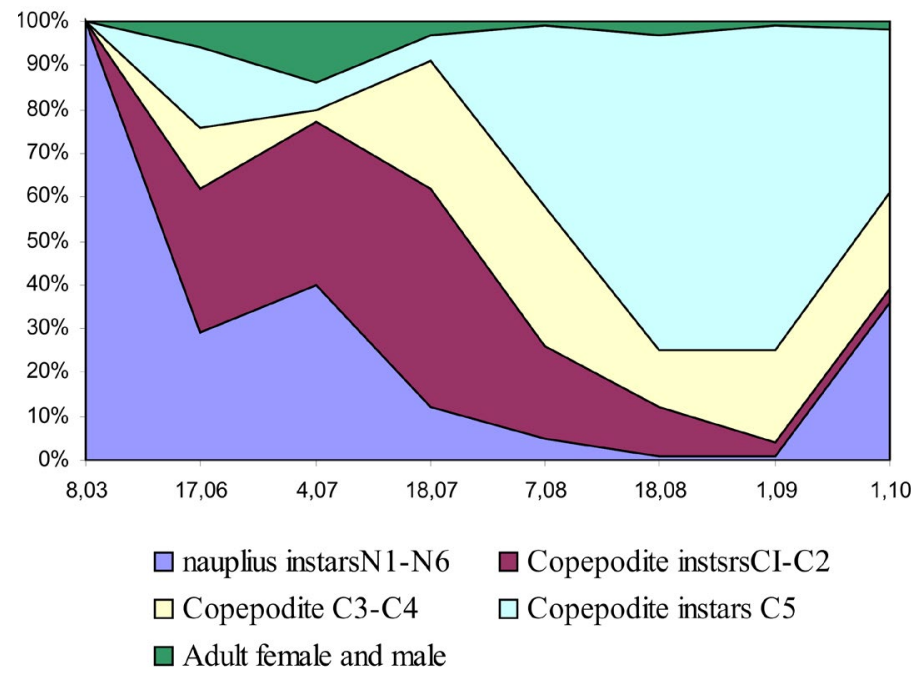

Fig. 3. Structure of population (\%) of Epischura baikalensis in Maloye More Strait.

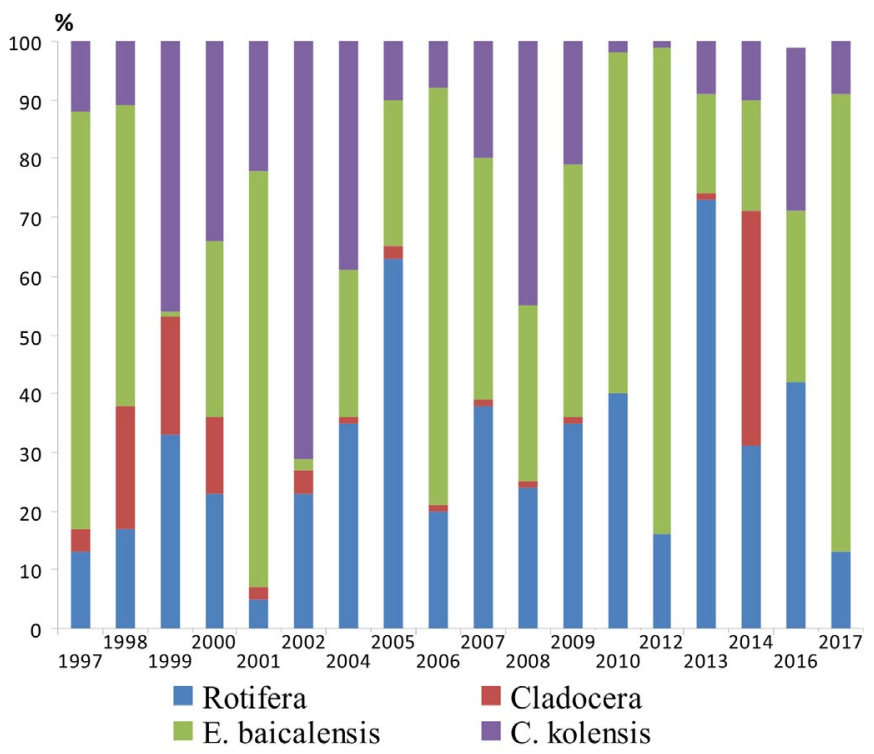

Fig. 4. Contribution (\%) of some taxonomic groups (rotifers, cladocerans, copepods) and E. baikalensis to the total zooplankton number.

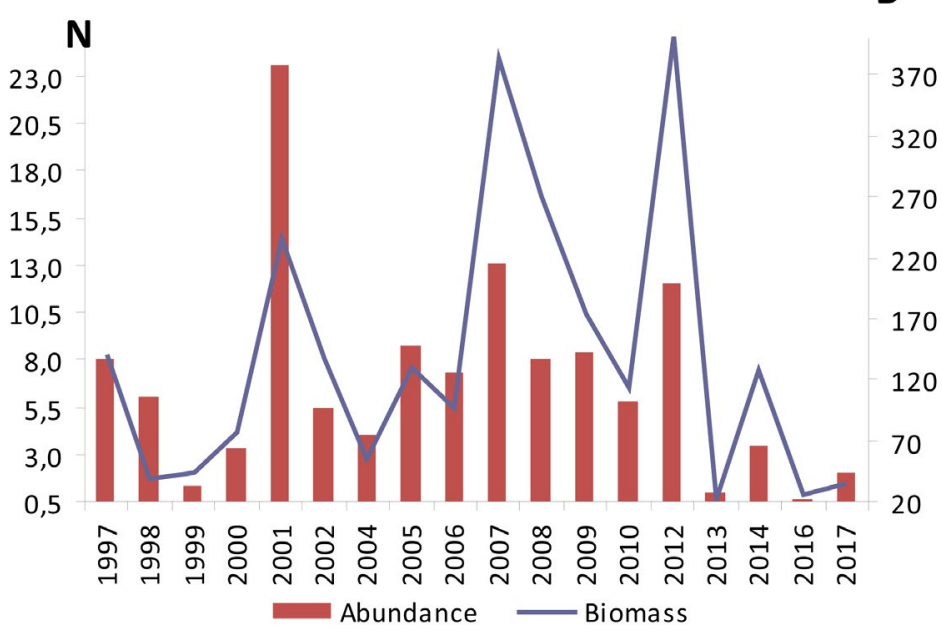

Fig. 5. Long-term dynamics of abundance (A, $10^{3}$ ind. $\mathrm{m}^{-3}$ ) and biomass $\left(\mathrm{B}, \mathrm{mg} \mathrm{m}^{-3}\right)$ of the E. baikalensis in the open part of Maloye More Strait. 
Russian)

Bondarenko N.A., Logacheva N.F. 2017. Structural changes in phytoplankton of the littoral zone of Lake Baikal. Hydrobiological journal 53: 16-24. DOI: 10.1615/HydrobJ. v53.i2.20

Garber B.I. 1941. Postembryonic development of Epischura baikalensis Sars. Izvestiya Akademii Nauk SSSR. Seriya biologicheskaya [Bulletin of the USSR Academy of Sciences. Biological sciences] 1: 106-114. (in Russian)

Hampton S.E., Izmesteva L.R., Moore M.V. et al. 2008. Sixty years of environmental change in the world's largest freshwater lake - lake Baikal, Siberia. Global Change Biology 14: 1-12. DOI: 1365-2486.2008.01616.x

Izmesteva L.R., Moore M.V., Hampton S.E. et al. 2016. Lake-wide physical and biological trends associated with warming in Lake Baikal. Journal of Great Lakes Research 42: 6-17. DOI: 10.1016/j.jglr.2015.11.006

Kiprushina K.N., Izmestieva L.R. 2009. Long-term and seasonal dynamics of zooplankton in the open part of southern Baikal. Bulletin of Tomsk State University 327: 202-207. (in Russian)

Kozhov M.M. 1962. Biology of Lake Baikal. Moscow: Academy of Sciences USSR. (in Russian)

Kozhov M.M., Pomazkova G.I. 1973. Lake Baikal. In: Smirnov N.N. (Ed.), Long-term indicators of zooplankton development in lakes. Moscow, pp. 133-178. (in Russian)

Kozhova O.M. 1971. Some modern problems of hydrobiological study of Siberia in connection with anthropogenization of water bodies. In: Kozhova O.M. (Ed.), Studies of hydrobiological regime of water bodies in East Siberia. Irkutsk, pp. 10-16. (in Russian)

Kozhova O.M. 1991. The problem of monitoring zooplankton. In: Israel Yu.A., Anokhin Yu.A. (Eds.), Monitoring of Lake Baikal. Leningrad, pp. 209-222. (in Russian)

Kozhova O.M., Melnik N.G. 1978. Instructions for processing samples by counting method. Irkutsk: ISU. (in Russian)

Kozhova O.M., Pavlov B.K. 1985. Ecological monitoring. Principles and methods. In: Kozhova O.M. (Ed.), Improving regional monitoring of Lake Baikal. Leningrad, pp. 22-37. (in Russian)

Kuimova L.N., Yakimova N.I., Sherstyankin P.P. 2015. Trends in climatic changes in temperature and ice conditions of Lake Baikal and the Arctic according to the observed data. In: 6th International Vereshchagin Baikal Conference, p. 34. (in Russian)

Naumova E.Yu., Zaidykov I.Yu., Tauson V.L. et al. 2015. Features of the fine structure and Si content of the mandibular gnathobase of four freshwater species of Epischura (Copepoda: calanoida). Journal of Crustacean Biology 35: 741-746. DOI: 10.1163/1937240X-00002385

Pavlov B.K., Pislegina E.V. 2004. Population assessment of Epischura baikalensis Sars in Lake Baikal for the implementation of environmental monitoring. In: 1st International symposium "Baikal. Current state of surface and underground hydrosphere of mountain countries", pp. 120-123. (in Russian)

Pislegina E.V., Pavlov B.K., Zilov E.A. 2004. Temporal variability of abundance and biomass of the Baikal zooplankton edifier species Epischura baikalensis Sars. In: 1st International symposium "Baikal. Current state of surface and underground hydrosphere of mountain countries", pp. 123 127. (in Russian)

Pislegina E., Zilov E. 2009. Long-tern dynamics of Baikal zooplankton and clime change. In: 13th World Lake Conference, pp. 110-111.

Pislegina E.V. 2010. Dynamics of pelagic zooplankton in Southern Baikal for 2007-2008. In: Problems of ecology. Workshop in the memory of Professor M.M. Kozhov, p. 92. (in Russian)

Sars G.O. 1900. On Epischura baikalensis, a new Calanoid from Baikal Lake. Ezhegodnik Zoologicheskago muzeya Imperatorskoy akademiy nauk [Yearbook of the Zoological museum of the Academy of Sciences] 5: 226-238.

Sheveleva N.G., Penkova O.G. 2005. Zooplankton in the southern part of Maloye More Strait (Lake Baikal). Inland Water Biology 4: 42-49. (in Russian)

Sheveleva N.G., Penkova O.G., Kiprushina K.N. 2009. Long-term dynamics of zooplankton abundance in open part of Maloye More Strait (Lake Baikal). Izvestiya Irkutskogo Gosudarstvennogo Universiteta [The Bulletin of Irkutsk State University] 2: 18-22. (in Russian)

Sheveleva N.G., Penkova O.G. 2018. Changes of the zooplankton community in Maloye More Strait during 20 years. In: International Conference «Freshwater Ecosystems Key Problems», pp. 331-332.

Shimaraev M.N., Sinyukovich V.N., Sizova L.N. et al. 2015. Changes in the ice-thermal and water regime of Lake Baikal in 1950-2014. In: 6th International Vereshchagin Baikal Conference, p. 34. (in Russian)

Timoshkin O.A., Malnik V.V., Sakirko V.M. et al. 2015. Ecological crisis in the coastal zone of Lake Baikal. In: 6th International Vereshchagin Baikal Conference, pp. 40-42. (in Russian)

Vilisova I.K. 1959. Zooplankton of Maloye More Strait. Trudy Baikalskoi limnologicheskoi stantsii AN SSSR [Proceedings of the Baikal Limnological Station of the Academy of Sciences of the USSR] 17: 275-312. (In Russian)

Zaidykov I.Y. 2016. Why does the cleaner of Lake Baikal need dental crowns? Science First Hand 44: 57-60.

Zaidykov I.Y., Mayor T.Y., Sukhanova L.V. et al. 2015. MtDNA polymorphism of Lake Baikal Epischura - an endemic key species of the plankton community. Russian Journal of Genetics 9: 1087-1090. DOI: 10.1134/S102279541508013X 